\title{
Clinical profile, quality of life and depressive symptoms of women with urinary incontince attending a university hospital
}

\section{Perfil clínico, qualidade de vida e sintomas depressivos de mulheres com incontinência urinária atendidas em hospital-escola}

Mara R. Knorst', Thais L. Resende', José R. Goldim²

\begin{abstract}
Objectives: To describe the characteristics of urinary incontinence (UI) and to evaluate its impact on health-related quality of life (QOL) and depressive symptoms in women referred for physical therapy at a university hospital. Methods: A descriptive cross-sectional study with demographic data collection related to UI. All women were evaluated through examination and also through depression and QOL questionnaires. Results: Forty-eight women were evaluated (53.8 \pm 10.9 years), $47.9 \%$ with mixed UI (MUI), 39.6\% with stress UI (SUI) and $12.5 \%$ with urge $\mathrm{UI}$ (UUI). In $50 \%$ of the cases the urinary loss lasted between 3.3 and 10 years. There was no significant difference in the pelvic floor muscle strength among the different types of $\mathrm{UI}(P>0.05)$. Depressive symptoms were detected in $37 \%$ of the women. Changes in the QOL were observed in all three groups of women with UI. According to the King's Health Questionnaire (KHQ), women with MUI presented more compromised health perception and greater physical, social, daily activity and personal relationship limitations $(\mathrm{P}<0.05)$. The women with MUI presented a worse health perception $(P<0.05)$ according to the WHOQOL-Bref. Conclusion: Depressive symptoms were detected in more than a third of the women whose quality of life was adversely affected and the greatest impact was observed in the patients with MUI.
\end{abstract}

Keywords: urinary incontinence; women's health; quality of life; depression.

\section{Resumo}

Objetivos: Descrever as características da incontinência urinária (IU) e avaliar seu impacto na qualidade de vida (QV) relacionada à saúde e aos sintomas depressivos de mulheres encaminhadas para atendimento fisioterapêutico em hospital universitário. Métodos: Estudo descritivo transversal com coleta de dados demográficos e dos relacionados à IU. Todas as mulheres foram avaliadas por meio de exame físico e por escalas de depressão e QV. Resultados: Foram avaliadas 48 mulheres (53,8 $\pm 10,9$ anos); 47,9\% com incontinência urinária mista (IUM), 39,6\% com incontinência urinária de esforço (IUE) e 12,5\% com incontinência urinária de urgência (IUU). Em 50\% dos casos, a perda urinária durou entre 3,3 e 10 anos. Não houve diferença na força da musculatura perineal nos diferentes tipos de IU $(P>0,05)$. Sintomas depressivos foram detectados em 37\% das mulheres. Observou-se alteração da $Q V$ nos três grupos de mulheres portadoras de IU. No King's Health Questionnaire (KHQ), portadoras de IUM apresentaram uma percepção de saúde mais comprometida, maiores limitações físicas, sociais, nas atividades diárias e nas relações pessoais $(P<0,05)$. No WHOQOL-Bref, observou-se uma pior percepção da saúde no grupo com IUM $(P<0,05)$. Conclusão: Foram detectados sintomas depressivos em mais de um terço das mulheres, cuja QV foi adversamente afetada, sendo o maior comprometimento observado nas mulheres com IUM.

Palavras-chave: incontinência urinária; saúde da mulher; qualidade de vida; depressão.

Received: 23/03/10 - Revised: 09/09/10 - Accepted: 08/02/11

\footnotetext{
${ }^{1}$ Faculty of Nursing, Nutrition and Physical Therapy, Pontifícia Universidade Católica do Rio Grande do Sul (PUCRS), Porto Alegre, RS, Brazil ${ }^{2}$ Institute of Geriatrics and Gerontology, PUCRS

Correspondence to: Mara Regina Knorst, Faculdade de Enfermagem, Nutrição e Fisioterapia, Prédio 12, Avenida Ipiranga, 6681, CEP 90.619-900, Porto Alegre, RS, Brasil, e-mail: mknorst@pucrs.br
} 


\section{Introduction : :}

The International Continence Society has recently modified the definition of urinary incontinence (UI) for "involuntary loss of urine that is a social or hygienic problem", emphasizing, therefore, the patient's complaint ${ }^{1}$.

The UI may be classified as stress urinary incontinence (SUI), urge urinary incontinence (UUI) and mixed urinary incontinence (MUI). SUI is characterized by loss due physical effort, through the intact urethra, without contraction of the detrusor muscle of the bladder. In UUI, the individuals feel a sudden and strong desire to urinate, however they are not able to control the mechanism of micturition. The MUI can be associated with both situations and also be a result of emotional aspects ${ }^{2}$.

Due to anatomical factors the prevalence of UI is higher in women than in men $^{2}$, affects women from all ages ${ }^{3}$, ranges from 8 to $34 \%$ in the elderly, occurs in 30 to $60 \%$ of the institutionalized elderly ${ }^{4}$ and may be a contributor for institutionalization ${ }^{3}$. The main risk factors for UI are previous history of hysterectomy; pregnancy; vaginal delivery and gestational or postpartum UI ${ }^{5}$; falling serum estrogen levels during the menopause; constipation; obesity; medications and surgeries that are able to cause reduction of the pelvic muscle tone and/or able to generate nerve compromise ${ }^{6}$.

The urinary incontinence causes discomfort, loss of selfconfidence and may lead to urinary tract infections, pressure ulcers and diseases of the perineal skin ${ }^{7}$. The medical, social, psychological and economic implications of this condition lead to changes in lifestyle ${ }^{8,9}$ and adversely affect the quality of life (QOL) in women. Feelings such as loneliness, sadness and depression are present in the incontinent women lives.

Women that present mild and moderate incontinence levels usually do not seek care, and the frequency for seeking treatment increases during the postmenopausal period, when the degree of urinary loss increases ${ }^{8}$. The initial assessment of patient aims to rule out specific diseases that can lead to urinary incontinence, to evaluate the severity of the condition, to make the diagnosis by the UI classification and to determinate the characteristics of the symptoms to determine an appropriate therapeutic approach. A clinical evaluation of pelvic floor muscles may be useful for studying the effect of intervention ${ }^{1}$.

The knowledge of the clinical profile of women with UI users of the physical therapy service may aid health managers in the formulation of more adequate work strategies and practices to the health needs of these women. Few studies related to this research topic have been conducted in Brazil ${ }^{6}$, and no similar study has been found in Rio Grande do Sul, Brazil. This study aimed to describe the characteristics of UI and to assess their impact on health-related QOL and depressive symptoms in women that have attended a physical therapy service in a university hospital.

\section{Methods :::}

A cross-sectional study was conducted at the Hospital São Lucas (HSL) of the Pontifícia Universidade Católica do Rio Grande do Sul (PUCRS), Porto Alegre, RS, Brazil from 2006 to 2008. The project was approved by the Ethics in Research Committee of the PUCRS (protocol 06/03194), and ethical principles were respected in accordance with the resolution 196/96 of CNS-MS. All the participants have read and signed the informed consent form.

Fifty consecutive women with medical diagnosis of UI who were referred from the Urogynecology clinic of HSL-PUCRS to the physical therapy department clinic were evaluated. Two women that had previous surgery aimed to correct urinary incontinence were excluded from the study.

The evaluations were carried out at the Department of Physical Therapy of HSL-PUCRS and were composed by anamnesis, functional assessment of the pelvic floor, two instruments for measuring QOL and one instrument to detect the presence of depression.

Data with regards to age, education, marital status, type of urinary incontinence, incontinence duration, circumstances of urinary loss, amount of urine lost, number of pregnancies, type of delivery, episiotomy, menopause, obesity, presence of genitourinary prolapse and presence of constipation were collected during the anamnesis. The participants described the amount of urine loss in droplets, dashes or whole bladder.

Functional assessment of pelvic floor was performed through perineometry and bidigital palpation, both with the woman in lithotomy position. For the perineometry, a digital perineometer (Kroman trademark) which detects the increase pressure induced by the contraction of the levator ani muscle (LAM) through a transvaginal electrode was used. The perineometry was performed three times, and the highest value in the Sauers scale was used as reference. Subsequently, the obtained values were converted into $\mathrm{cmH}_{2} \mathrm{O}$, taking into account that 28 Sauers units are equal to a pound that, on the other hand, corresponds to $0.49 \mathrm{cmH}_{2} \mathrm{O}$.

The LAM strength was also assessed by the bidigital palpation. The ability to contract this muscle was graded based on the Ortiz ${ }^{10}$ scale, ranging from 0 to 5 , where zero is the absence of muscle contraction and five is a strong and sustained contraction for more than five seconds.

The impact of incontinence on QOL was measured using two questionnaires, being one general, the World Health Organization Quality of Life -BREF questionnaire (WHOQOL-bref) and a specific questionnaire for UI patients, the "King's Health Questionnaire" (KHQ).

The KHQ consists of 21 questions divided into eight domains: general health perception, incontinence impact, activity 
limitations of daily life, physical limitations, social limitations, personal relationships, emotions, sleep/energy. The KHQ is scored for each of its domains, therefore, there is no total score. The scores range from 0 to 100 and the higher the score, the worse is the QOL related to that domain ${ }^{11}$.

The WHOQOL-bref questionnaire is divided into four domains: physical health, psychological health, social relationships and environment. Data obtained using the WHOQOL-bref were evaluated for each specific domain, being the higher the score (maximum $=100$ ), the better the QOL related to that domain ${ }^{12}$.

To assess the presence of depressive symptoms the General Hospital Depression Scale (GHDS) which is composed of six items was used. A total score equal to or higher than three is suggestive of depression ${ }^{13}$. Additionally, a self-perception question "Do you feel depressed?" was added and the answer is reported as a yes/no format.

The sample size calculation (45 women) was performed using the PEPI statistical program based on the estimated effect observed in a previous study of physical therapy intervention in the UI, with a significance level of $95 \%$, a estimated positive result of $74 \%$ and $10 \%$ of standard deviation. Data analysis was performed by the statistical package SPSS 11.0. The Kolmogorov-Smirnov test was used to assess the distribution of quantitative variables. The comparison of the incontinence type was performed with the One-Way Analysis Variance (ANOVA) test, and for the remaining analysis the nonparametric test of Kruskal-Wallys was used. Comparisons with regards to the UI types were performed by Pearson's chi-square test. The presence of depressive symptoms detected by the GHDS and by the self-perception of depression question was compared by the McNemar test, and the level of agreement between these variables was investigated using the Kappa coefficient. The level of significance for all analysis was $\alpha \leq 0.05$.

\section{Results : :}

Forty-eight women with a mean age $53.8 \pm 10.8$ years participated in the present study. The majority of women was married (64.6\%), had complete or incomplete elementary education (60.4\%) and residing outside Porto Alegre, Brazil (58.3\%). Data with regards to age, education level, marital status and duration of incontinence according to UI type are shown in Table 1.

With regards to the clinical diagnosis of the participants, 23 women (47.9\%) were classified as having MUI; 19 women $(39.6 \%)$ had SUI and 6 women $(12.5 \%)$ were classified as having UUI. The mean duration of urinary incontinence complaint was $7.9 \pm 6.4$ years, and $50 \%$ of women presented urinary loss that lasted between 3.3 and 10 years.

Half of the women had two to four pregnancies, and only two nulliparous were observed in our sample. Women with MUI had significantly more pregnancies than women with SUI and UUI ( $p=0.01)$, being the median in the MUI group of three pregnancies, while SUI and UUI groups showed a median of 2

Table 1. Sample characteristics: data relative to the total sample and according to the type of incontinence.

\begin{tabular}{|c|c|c|c|c|c|}
\hline \multirow{2}{*}{ Variables } & \multirow{2}{*}{$\begin{array}{c}\text { Total } \\
(n=48)\end{array}$} & \multicolumn{4}{|c|}{ Type of Urinary Incontinence } \\
\hline & & SUI $(n=19)$ & UUI $(n=6)$ & $\operatorname{MUI}(n=23)$ & $p$ \\
\hline \multicolumn{5}{|l|}{ Age (years) } & \multirow{3}{*}{$0.221 \theta$} \\
\hline Mean $( \pm S D)$ & $53.8(10.8)$ & $50.9(8.2)$ & $59.3(12.1)$ & $54.8(12.1)$ & \\
\hline Minimum - Maximum & $35-78$ & $37-67$ & $42-77$ & $35-78$ & \\
\hline \multicolumn{5}{|l|}{ Education * } & \multirow{4}{*}{$0.027 \phi$} \\
\hline Illiterate & $4(8.3)$ & $0(0.0)$ & $0(0.0)$ & $4(17.4)$ & \\
\hline $\begin{array}{l}\text { Complete and incomplete primary education } \\
\text { (up to } 8 \text { years) }\end{array}$ & $29(60.4)$ & $11(57.9)$ & $2(33.3)$ & $16(69.6)$ & \\
\hline $\begin{array}{l}\text { Complete and incomplete high school } \\
\text { (9 years or more) }\end{array}$ & $15(31.3)$ & $8(42.1)$ & $4(66.7)$ & $3(13.0)$ & \\
\hline \multicolumn{5}{|l|}{ Marital status * } & \multirow{5}{*}{$0.212 \phi$} \\
\hline Married & $31(64.6)$ & $14(73.7)$ & $3(50.0)$ & $14(60.9)$ & \\
\hline Divorced & $5(10.4)$ & $2(10.5)$ & $1(16.7)$ & $2(8.7)$ & \\
\hline Single & $4(8.3)$ & $3(15.8)$ & $0(0.0)$ & $1(4.3)$ & \\
\hline Widow & $8(16.7)$ & $0(0.0)$ & $2(33.3)$ & $6(26.1)$ & \\
\hline \multicolumn{5}{|l|}{ Duration of complaints (years) } & \\
\hline Median $\left(\mathrm{P}_{25}-\mathrm{P}_{75}\right) \nabla$ & $7.9(6.4)$ & $6.1(2.9)$ & $9.3(9.1)$ & $9.0(7.5)$ & 0.673 \\
\hline \multicolumn{5}{|l|}{ Number of pregnancies } & \\
\hline Median $\left(\mathrm{P}_{25}-\mathrm{P}_{75}\right) \nabla$ & $6.5(3-10)$ & $5(4-8)$ & $8(2-15)$ & $7(2-15)$ & $8(2-15)$ \\
\hline
\end{tabular}

$\mathrm{SUI}=$ stress urinary incontinence; $\mathrm{UUI}=$ urge urinary incontinence; $\mathrm{MUI}=$ mixed urinary incontinence; $\mathrm{SD}=$ standard deviation; ${ }^{*}$ Values presented in the form of $\mathrm{n}(\%)$, where the percentage was obtained based on the total number of cases in the sample or the total of each category of $\mathrm{Ul} ; \boldsymbol{\theta}=\mathrm{O}$ One Way Analysis of variance (ANOVA); $\phi=$ Chi-square test not validated due to the presence of more than $20 \%$ of cases with expected frequency below 5 ; = Kruskal-Wallys; $\nabla=$ P25 concentrates $25 \%$ of the sample with values less than or equal to that set by $\mathrm{P} 25 ; \mathrm{P} 75=$ concentrates $75 \%$ of the sample with values less than or equal to that defined by P75. 
and 2.3 pregnancies, respectively. Regarding the type of delivery, $81.3 \%$ of the participants had a vaginal delivery, $68.4 \%$ reported having an episiotomy, and $31.3 \%$ underwent cesarean section. Thirty-six women presented some type of prolapse, which was predominantly observed in women with SUI (84.2\%). Thirty-five women $(72.9 \%)$ were in the menopause; all UUI participants were in the menopause. Intestinal constipation was a symptom reported in $45.2 \%$ of the participants.

In all circumstances of loss of urine evaluated in this study, there were statistically significant differences when comparing the three types of UI $(\mathrm{P}<0.05)$. Coughing, sneezing, laughing, jumping, experiencing orgasm and walking were the circumstances that were associated to the urine loss in the SUI and MUI groups, while the urine loss in the presence of full bladder is more frequent in women with UUI.

From all women $87.5 \%$ reported urine loss in droplets and dashes. The amount of urine lost was compared between the different UI types; being urine loss in dashes predominating in all group types. However, $21.7 \%$ of women with MUI reported complete urinary loss.

The median of contraction strength of the pelvic floor muscles measured through the perineometer in all participants was $0.64 \mathrm{cmH}_{2} \mathrm{O}$, being $50 \%$ of women presented muscle strength between 0.38 to $1 \mathrm{cmH}_{2} \mathrm{O}$. Comparison of muscle strength among the different incontinence type groups showed that women with MUI presented the highest median $\left(0.71 \mathrm{cmH}_{2} \mathrm{O}\right)$ and women with UUI presented the lowest median $\left(0.58 \mathrm{cmH}_{2} \mathrm{O}\right)$. However, this difference was not statistically significant $(\mathrm{P}>0.05)$.

The median of the bidigital palpation grade of the LAM was 4 , being $50 \%$ of the participants had the contraction strength grades of this muscle between 3 and 5 . The median estimates according to the incontinence type groups were very similar, with no between-group differences $(\mathrm{P}>0.05)$.

Depressive symptoms were detected in $39.6 \%$ of women by the GHDS and in $47.9 \%$ of the cases by the question "Do you feel depressed?", with a significant correlation between the two measures $(\mathrm{P}<0.001)$. There was no significant difference between the results obtained by the two measures used to investigate depression ( $\mathrm{P}>0.05)$, observing a moderate level of agreement between the measures $(\mathrm{k}=0.644, \mathrm{P}<0.001)$.

Table 2 shows the results of the KHQ. There were significant differences among the three UI types groups in relation to general health perception and the highest and the worst scores

Table 2. Descriptive measures for the quality of life instrument specific for individuals with urinary incontinence, the "King's Health Questionnaire; data relative to the total sample and according to the type of incontinence.

\begin{tabular}{|c|c|c|c|c|c|}
\hline \multirow{2}{*}{ Variables } & \multirow{2}{*}{$\begin{array}{c}\text { Total } \\
(\mathrm{n}=48)\end{array}$} & \multicolumn{4}{|c|}{ Type of Urinary Incontinence } \\
\hline & & SUI $(n=19)$ & UUI $(n=6)$ & MUI $(n=23)$ & $P$ \\
\hline \multicolumn{5}{|c|}{ General health perception } & \multirow{3}{*}{0.020} \\
\hline Median & 50 & 25 & 37,5 & 50 & \\
\hline$\left(\mathrm{P}_{25}-\mathrm{P}_{75}\right) \nabla$ & $(25-50)$ & $(25-50)$ & $(18.7-62.5)$ & $(50-50)$ & \\
\hline \multicolumn{5}{|c|}{ Impact of incontinence } & \multirow{3}{*}{0.086} \\
\hline Median & 66.7 & 66.7 & 33.3 & 66.7 & \\
\hline$\left(\mathrm{P}_{25}-\mathrm{P}_{75}\right) \nabla$ & $(33.3-100)$ & $(33.3-66.7)$ & $(33.3-75)$ & $(33.3-100)$ & \\
\hline \multicolumn{5}{|c|}{ Daily activities limitations } & \multirow{3}{*}{0.022} \\
\hline Median & 33.3 & 33.3 & 33.3 & 50 & \\
\hline$\left(\mathrm{P}_{25}-\mathrm{P}_{75}\right) \nabla$ & $(33.3-66.7)$ & $(16.7-33.3)$ & $(0-83.3)$ & $(33.3-66.7)$ & \\
\hline \multicolumn{5}{|c|}{ Physical limitations } & \multirow{3}{*}{0.011} \\
\hline Median & 41.7 & 33.3 & 25.0 & 66.7 & \\
\hline$\left(\mathrm{P}_{25}-\mathrm{P}_{75}\right) \nabla$ & $(33.3-66.7)$ & $(16.7-50)$ & $(16.7-62.5)$ & $(33.3-83.3)$ & \\
\hline \multicolumn{5}{|c|}{ Social limitations } & \multirow{3}{*}{0.013} \\
\hline Median & 33.3 & 22.2 & 16.7 & 33.3 & \\
\hline$\left(\mathrm{P}_{25}-\mathrm{P}_{75}\right) \nabla$ & $(2.78-55.6)$ & $(0.0-33.3)$ & $(0.0-50)$ & $(33.3-66.7)$ & \\
\hline \multicolumn{5}{|c|}{ Personal relationships } & \multirow{3}{*}{0.005} \\
\hline Median & 33.3 & 0 & 0 & 33.3 & \\
\hline$\left(\mathrm{P}_{25}-\mathrm{P}_{75}\right) \nabla$ & $(0-50)$ & $(0-33.3)$ & $(0-25)$ & $(33.3-66.7)$ & \\
\hline \multicolumn{5}{|l|}{ Emotions } & \multirow{3}{*}{0.058} \\
\hline Median & 44.4 & 33.3 & 38.9 & 55.5 & \\
\hline$\left(\mathrm{P}_{25}-\mathrm{P}_{75}\right) \nabla$ & $(22.2-77.8)$ & $(11.1-44.4)$ & $(8.3-75)$ & $(33.3-88.8)$ & \\
\hline \multicolumn{5}{|c|}{ Sleep and energy } & \multirow{3}{*}{0.275} \\
\hline Median & 33.3 & 33.3 & 33.3 & 50 & \\
\hline$\left(\mathrm{P}_{25}-\mathrm{P}_{75}\right) \nabla$ & $(33.3-50)$ & $(16.7-50)$ & $(12.5-66.7)$ & $(33.3-50)$ & \\
\hline \multicolumn{5}{|c|}{ Measures of gravity } & \multirow{3}{*}{0.058} \\
\hline Median & 66.7 & 53.3 & 53.3 & 73.3 & \\
\hline$\left(P_{25}-P_{75}\right) \nabla$ & $(46.7-73.3)$ & $(46.7-66.7)$ & $(30-75)$ & $(60-86.7)$ & \\
\hline
\end{tabular}

SUI = stress urinary incontinence; UUI = urge urinary incontinence; MUI = mixed urinary incontinence; = Kruskal-Wallys Test; $\nabla=$ Percentile 25 (P25) and Percentile 75 (P75). 
were observed in the MUI group ( $\mathrm{P}=0.02)$. Similarly, activity limitations of daily life, physical limitations, social limitations and personal relationships domains were significantly more affected in this group of women $(\mathrm{P}<0.05)$.

The results regarding the WHOQOL- bref are shown in Table 3. A significant difference in the initial question "How is your health?" was observed. Women with MUI had significantly lower mean score in this question compared to the other UI groups types ( $\mathrm{P}=0.032)$. Similarly, in question 2 , which also address information related to the health perception, the lowest score was observed in the MUI group type ( $\mathrm{P}=0.046)$. There were no differences between groups in the remaining domains of the questionnaire.

\section{Discussion $::$.}

The results of this study showed that women attending physical therapy service at a university hospital in Porto Alegre, RS, Brazil were middle-aged, were or had been married and had a low education level. These results are supported by Figueiredo et al. ${ }^{6}$ who found women aged between 40 and
59 years-old and with complete and incomplete elementary education. The similarity between the two studies also occurred with regard to the prevalence of the UI type. In both studies the prevalence of MUI type was higher compared to the other types, being $48 \%$ in the present study and $63 \%$ in the Figueiredo et al. ${ }^{6}$ study. On the other hand, a large observational study carried out in Norway, the Norwegian EPINCONT Study ${ }^{14}$, demonstrated that from the 27,936 women aged grater than 20 years who participated in the study, $25 \%$ had UI. This study ${ }^{14}$ also showed that the prevalence of UI increased with age and half of the women included in this study had SUI, 36\% MUI and 11\% UUI. Similarly, Isherwood and Rane ${ }^{15}$ found SUI as the most prevalent type of UI in younger women, with a mean age of 41 years.

The prevalence of any UI type is likely to increase until middle-age, to decrease between 50 and 70 years-old and to increase with a more advanced age ${ }^{1,5}$. In the present study, it was observed that the highest mean of age occurred in women with UUI and the lowest mean of age in women with SUI (59.3 versus 50.9 years). An inverse relation between SUI and age has been described previously in another study $(\mathrm{r}=-0.380, \mathrm{p}<0.001)^{16}$.

Table 3. Descriptive measures for the generic instrument to assess quality of life, the WHOQOL-bref; data relative to the total sample and according to the type of incontinence.

\begin{tabular}{|c|c|c|c|c|c|}
\hline \multirow{2}{*}{ Variables } & \multirow{2}{*}{$\begin{array}{c}\text { Total } \\
(\mathrm{n}=48)\end{array}$} & \multicolumn{4}{|c|}{ Type of Urinary Incontinence } \\
\hline & & SUI $(n=19)$ & UUI $(n=6)$ & MUI $(n=23)$ & $P^{*}$ \\
\hline \multicolumn{5}{|c|}{ "How is your health?" } & \multirow{3}{*}{0.032} \\
\hline Mean (SD) & $57.2(21.7)$ & $67.1(20.5)$ & $54.2(29.2)$ & $48.7(17.1)$ & \\
\hline Median $\left(P_{25}-P_{75}\right)$ & $50(50-75)$ & $50(50-75)$ & $62.5(37.5-75)$ & $50(50-50)$ & \\
\hline \multicolumn{5}{|c|}{ General perception (Q1 \& Q2) } & \multirow{3}{*}{0.132} \\
\hline Mean (SD) & $56.2(16.3)$ & $59.2(14.9)$ & $64.6(18.4)$ & $51.6(16.1)$ & \\
\hline $\operatorname{Median}\left(P_{25}-P_{75}\right)$ & $62.5(40.6-62.5)$ & $62.5(50-75)$ & $68.7(46.8-78.1)$ & $50(37.5-62.5)$ & \\
\hline \multicolumn{5}{|c|}{ Perceived quality of life } & \multirow{3}{*}{0.507} \\
\hline Mean (SD) & $61.5(14.5)$ & $64.5(15.2)$ & $58.3(12.9)$ & $59.8(14.6)$ & \\
\hline Median $\left(P_{25}-P_{75}\right)$ & $50(50-75)$ & $75(50-75)$ & $50(50-75)$ & $50(50-75)$ & \\
\hline \multicolumn{5}{|l|}{ Perceived health } & \multirow{3}{*}{0.046} \\
\hline Mean (SD) & $51.0(25.2)$ & $53.9(19.1)$ & $70.8(29.2)$ & $43.5(26.3)$ & \\
\hline Median $\left(P_{25}-P_{75}\right)$ & $50(25-75)$ & $50(50-75)$ & $75(43.7-100)$ & $50(25-50)$ & \\
\hline \multicolumn{5}{|l|}{ Physical } & \multirow{3}{*}{0.750} \\
\hline Mean (SD) & $56.9(9.7)$ & $58.1(8.1)$ & $54.7(6.2)$ & $56.5(11.8)$ & \\
\hline Median $\left(P_{25}-P_{75}\right)$ & $57.1(50-64.3)$ & $57.1(53.6-64.3)$ & $55.3(49.1-58.9)$ & $57.1(50-64.3)$ & \\
\hline \multicolumn{5}{|l|}{ Psychological } & \multirow{3}{*}{0.162} \\
\hline Mean (SD) & $55.5(12.2)$ & $57.8(10.2)$ & $61.1(10.7)$ & $52.2(13.5)$ & \\
\hline Median $\left(P_{25}-P_{75}\right)$ & $58.3(46.9-62.5)$ & $62.5(50-62.5)$ & $62.5(57.3-65.6)$ & $54.2(45.8-58.3)$ & \\
\hline \multicolumn{5}{|c|}{ Personal relationships } & \multirow{3}{*}{0.420} \\
\hline Mean (SD) & $69.9(15.4)$ & $71.9(14.5)$ & $75.0(11.8)$ & $67.0(16.9)$ & \\
\hline $\operatorname{Median}\left(\mathrm{P}_{25}-\mathrm{P}_{75}\right)$ & $66.7(58.3-81.3)$ & $75(58.3-75)$ & $75(64.6-85.4)$ & $66.7(58.3-83.3)$ & \\
\hline \multicolumn{5}{|l|}{ Environment } & \multirow{3}{*}{0.065} \\
\hline Mean (SD) & $57.0(10.6)$ & $59.8(6.9)$ & $61.9(6.7)$ & $53.4(12.8)$ & \\
\hline Median $\left(P_{25}-P_{75}\right)$ & $56.3(50-65.6)$ & $59.4(53.1-65.6)$ & $62.5(55.4-68.7)$ & $50(43.7-62.5)$ & \\
\hline
\end{tabular}

SUI=stress urinary incontinence; UUl=urge urinary incontinence; MUI=mixed urinary incontinence; *=Analysis of Variance (One Way); SD=standard deviation. 
The study performed by Lewis ${ }^{17}$ demonstrated that $75 \%$ of 827 women with UI took about three years to seek care. This same difficulty in seeking care was observed among women of the present study, in which $50 \%$ of the sample had incontinence lasting for between 3 and 10 years. A lower level of care-seeking was previously described ${ }^{8}$ in women with a mild to moderate levels of incontinence, with the frequency of health care seeking increasing during the postmenopausal period, when the level of urinary loss increases ${ }^{8}$. This situation was confirmed by the present study, since $72.9 \%$ of women match this situation.

Regarding the number of pregnancies, $50 \%$ of participants had between two and four pregnancies, whereas Figueiredo et al. $^{6}$ showed that $42 \%$ had one to three pregnancies. In this study, we found that women diagnosed with MUI had a greater number of pregnancies, being this type of UI significantly associated with vaginal delivery, while the SUI type was associated with cesarean section. In a study performed by Guarise et al. ${ }^{18}$, there was no increased risk of urinary incontinence among women who had one or more pregnancies, as well as among women who had one or more deliveries when compared with those who had no pregnancies or childbirth.

The UI has been associated with neuromuscular damage of the pelvic floor that occur during the vaginal delivery, especially in primiparous women, however, there are still controversies about whether UI is due to pregnancy or due to the type of delivery ${ }^{19}$. It was observed in this study that $81.3 \%$ of the participants had vaginal delivery, being this percentage higher than the findings of $76 \%$ observed in the study performed by Figueiredo et al. ${ }^{6}$ with a similar sample.

According to Neumann ${ }^{20}$, women who had never had vaginal delivery, women who are young and those who have not had prolapse may have UI. These findings were confirmed in this study, since that from all participants, nine had never had vaginal delivery, two never had been pregnant and $25 \%$ have not had any type of prolapse.

In this study, the circumstances of urinary loss that predominated in women with SUI and MUI were coughing and sneezing, followed by laughing. For women with MUI, the urine loss also occurs in others circumstances such as jumping, walking and experiencing an orgasm. The situation of being unable to stop leakage before reaching the toilet was described as the most common circumstance in women with UUI. Other authors ${ }^{2,6}$ refer to urinary loss during efforts and urgency as the predominant signs and symptoms in women with UI.

The manufacturer of the perineometer used in this study established 28 Sauers (1pound-0.49 $\mathrm{cmH}_{2} \mathrm{O}$ ) as the minimum value to be obtained in the examination of a healthy musculature. It was observed a mean of 42.1 Sauers $\left(0.73 \mathrm{cmH}_{2} \mathrm{O}\right)$ to the strength of the perineal muscles, even in women with SUI and MUI, in which muscle weakness is considered as determinant for urinary leakage. However, it is necessary to consider that the presence of prolapse may interfere in the measurements performed by the perineometry.

In the bidigital evaluation to detect the level of strength of the pelvic floor muscles, we found that $50 \%$ of women presented a strength grade ranging from 3 to 5 . The Royal College of Obstetricians and Gynaecologists (RCOG) recognizes that there still is a lack of scientific evidence for the clinical use of the digital assessment of pelvic floor muscles. However, the RCOG's technical report states that the presence or absence of contraction of the pelvic floor muscles may orientate the treatment decisions ${ }^{1}$. The bidigital test is a low cost test that can be used in primary care, that can help to improve the physical therapy assessment and interventions. A major issue is that this test must be performed by the same examiner at the beginning and end of treatment ${ }^{1}$, as we have performed in our study.

Depressive symptoms were investigated in the present study through the application of DHGS and the investigation of the self-perception of depression in women. Our results showed a significant association between depression measured through the DHGS and the self- perception question, suggesting that the simple question "Do you feel depressed?" may be useful in screening for depressive symptoms in women with urinary incontinence and it justifies its use in the routine care of this population. This data is particularly relevant in face of the findings that depression is significantly more frequent in women with urinary incontinence ${ }^{3,21}$. Depression is also associated with increased mortality, comorbidities, use of health services and decreased quality of life ${ }^{22}$. In this study, almost $40 \%$ of participants showed results suggestive of depression, higher than that observed in a study performed by Ko et al. ${ }^{3}$ in which approximately $28 \%$ of the population with UI had felt depressed or lost interest in activities that before they usually carried out, compared with $15.4 \%$ of the continent group. This difference between the prevalence by Ko et al. ${ }^{3}$ and our study is probably due to differences between the samples recruited, both in terms of composition, as well as the sample size.

Besides the depression, in $15 \%$ to $30 \%$ of the cases, UI affects the social, occupational, physical and sexual life of the women of all ages. The psychosocial impact can be more devastating than the consequences on health, with multi and comprehensive effects that influence daily activities, social interaction and self-perception of health status ${ }^{23}$.

Urinary symptoms of KHQ that women reported more often as "a lot" to affect them were urinary urgency and SUI 
(41.6\%), urinary frequency (35.4\%) and the urge incontinence (31.2\%). Rett et al. ${ }^{9}$ demonstrated that the urinary frequency (65.4\%), nocturia and urinary urgency (57.7\%) were the symptoms that most affected women.

In order to assess QOL, we used a UI-specific questionnaire, the KHQ and a general one, the WHOQOL-bref. In both questionnaires, there was a negative impact of UI on QOL of women, with median scores in the KHQ ranging from 33.3 to 66.7 and the WHOQOL-bref from 51.0 to 69.9, confirming the results of other studies, which showed median scores ranging between 33.0 and 100.0 and between 40 and $58^{24}$.

Comparing the results of the two QOL questionnaires suggests that, on one hand, both instruments measure the QOL outcomes in women with involuntary urine loss, on the other hand, the KHQ is more sensitive to detect differences between the various UI types. In the KHQ, the highest and the lowest scores in all items evaluated were observed in women with MUI. In five out of nine items, the difference between women with SUI and UUI was statistically significant (general health perception, daily activitiy limitations, physical limitations, social limitations and personal relationships), showing the greatest negative impact this type of UI in quality of life. In the WHOQOL-Bref, women with MUI also had the worst scores in six out of eight domains investigated, although the between-group difference was statistically significant in only two domains (situation and health perception).

One aspect that needs to be further studied is the relationship between the volume of urinary loss and QOL. In the present study, the urinary loss was classified as droplets, dashes or whole bladder. Few studies have used a similar description of the intensity of urinary loss, and, in most of them the urinary loss is described as small, moderate or severe. Our results showed that women with MUI presented a more significant urinary loss. Furthermore, these women presented a lower level of QOL. These results suggest that besides the UI type, the amount of urinary loss may influence the QOL of incontinent women. Further investigations are needed to clarify this issue.

This study has limitations that should be discussed. Firstly, an objective method to quantify the urinary loss was not used, but instead a description given by the participants as droplets, dashes or whole bladder was used. A second limitation was the small number of women with UUI, notwithstanding the most compromised group, MUI, is also the most prevalent in the study

In conclusion, the results show that the most common UI type in this sample was the MUI; depressive symptoms may follow the disease; and it causes a negative impact on the QOL of women, being these effects more pronounced in women with MUI. However, these results reflect the reality of a specific population who attends a university hospital and do not necessarily reflect the reality of women with UI in general. These results may contribute to the approach of evaluation and treatment of UI in other services.

\section{References : :}

1. Adams E, Bardsley A, Crumlin L, Currie I, Evans L, Haslam J. Urinary incontinence the management of urinary incontinence in women. Published by the RCOG Press at the Royal College of Obstetricians and Gynaecologists, 27 Sussex Place, Regent's Park, London NW1 4RG. October 2006. Acesso em 28/10/2008. Available in: http://www.nice.org.uk/nicemedia/ pdf/CG40fullguideline.pdf.

2. Abrams P, Cardoso L, Fall M, Griffiths D, Rosier P, Ulmsten U, et al. The standardisation of terminology of lower urinary tract function: report from the standardisation sub-committee of International Continence Society. Urology. 2003;61(1):37-49.

3. Ko Y, Lin SJ, Salmon JW, Bron MS. The impact of urinary incontinence on quality of life of the elderly. Am J Manag Care. 2005;11(4 Suppl):S103-11.

4. Wagg A, Potter J, Peel P, Irwin P, Lowe D, Pearson M. National audit of continence care for older people: management of urinary incontinence. Age Ageing. 2008;37(1):39-44.

5. Papanicolaou S, Hunskaar S, Lose G, Sykes D. Assessment of bothersomeness and impact on quality of life of urinary incontinence in women in France, Germany, Spain and the UK. BJU Int. 2005;96(6):831-8.

6. Figueiredo EM, Lara J0, Cruz MC, Quintão DMG, Monteiro MVC. Perfil sociodemográfico e clínico de usuárias de serviço de fisioterapia uroginecológica da rede pública. Rev Bras Fisioter. 2008;12(2):136-42

7. Dumoulin C, Hay-Smith J. Pelvic floor muscle training versus no treatment for urinary incontinence in women. A Cochrane systematic review. Eur J Phys Rehabil Med. 2008;44(1):47-63.

8. Higa R, Lopes MHBM. Porque profissionais de enfermagem com incontinência urinária não buscam tratamento. Rev Bras Enferm. 2007;60(5):503-6.
9. Rett MT, Simões JA, Herrmann V, Gurgel MSC, Morais SS. Qualidade de vida em mulheres após tratamento da incontinência urinária de esforço com fisioterapia. Rev Bras Ginecol Obstet. 2007;29(3):134-40.

10. Ortiz 0. Valoración dinâmica de la disfunción perineal da classificación. Boletim de La Sociedad Latino Americana de Uroginecologia y Cirurgia Vaginal. 1994;1(2):7-9.

11. Tamanini JTN, D’Ancona CAL, Botega NJ, Rodrigues Netto Jr N. Validação do "Kings Health Questionaire" para o português em mulheres com incontinência urinária. Rev Saúde Pública. 2003;37(2):203-11.

12. Fleck MPA, Chachamovich E, Trentini CM. Projeto WHOQOL-OLD: método e resultados de grupos focais no Brasil. Rev Saúde Pública. 2003;37(6):793-9.

13. Machado SCEP, Goldim JR, Fleck MPA, Eizirik CL. Performance of a new depression scale in a Brazilian general hospital. Acta Psychiatrica Scandinavica. 2004;110(241 Supl):13.

14. Hannestad YS, Rortveit G, Sandvik H, Hunskaar S; Norwegian EPINCONT study. Epidemiology of Incontinence in the County of Nord-Trøndelag. A community-based epidemiological survey of female urinary incontinence: the Norwegian EPINCONT study. Epidemiology of Incontinence in the County of Nord- Trøndelag. J Clin Epidemiol. 2000;53(11):1150-7.

15. Isherwood PJ, Rane A. Comparative assessment of pelvic floor strength using a perineometer and digital examination. BJOG. 2000;107(8):1007-11.

16. Coppola L, Caserta F, Grassia A, Mastrolorenzo L, Altrui L, Tondi G, et al. Urinary incontinence in the elderly: relation to cognitive and motor function. Arch Gerontol Geriatr. 2002;35(1):27-34 
17. Lewis D. Incontinence survey report. In: Getliffe K, Dolman M. Promoting continence: a clinical and research resource. London: Bailliere Tindall; 1997.

18. Guarisi T, Pinto Neto AM, Osis MJ, Pedro AO, Paiva LHC, Faúndes A. Incontinência urinária entre mulheres climatéricas brasileiras: inquérito domiciliar. Rev Saúde Pública. 2001; 35(5):428-35.

19. Menta S, Schirmer J. Relação entre a pressão muscular perineal no puerpério e 0 tipo de parto. Rev Bras Ginecol Obstet. 2006;28(9):523-9.

20. Neumann PB, Grimmer KA, Grant RE, Gill VA. Physioterapy for female stress urinary incontinence: a multicentre observational study. Aust N Z J Obstet Gynaecol. 2005;45(3):226-32.
21. Meade-D'Alisera P, Merriweather T, Wentland M, Fatal M, Ghafar M. Depressive symptoms in women with urinary incontinence: a prospective study. Urol Nurs. 2001;21(6):397-9.

22. Dugan E, Cohen SJ, Bland DR, Preisser JS, Davis CC, Suggs PK, et al. The association of depressive symptoms and urinary incontinence among older adults. J Am Geriatr Soc. 2000;48(4):413-6.

23. Lopes MHBM, Higa R. Restrições causadas pela incontinência urinária à vida da mulher. Rev Esc Enferm USP. 2006;40(1):34-41.

24. Huang AJ, Brown JS, Kanaya AM, Creasman JM, Ragins AI, Van Den Eeden SK, et al. Quality-oflife impact and treatment of urinary incontinence in ethnically diverse older women. Arch Intern Med. 2006;166(18):2000-6. 